\title{
Comparative Study of Morphological Characteristics and Body Composition between Elite Basketball Players from Different Regions
}

\author{
Bojan Masanovic ${ }^{1}$, Marina Vukotic ${ }^{1}$, Velisa Vukasevic ${ }^{2}$ \\ 'University of Montenegro, Faculty for Sport and Physical Education, Niksic, Montenegro, ${ }^{2}$ Basketball Club Vizura, Belgrade, Serbia
}

\begin{abstract}
The purpose of this study was to describe morphological characteristics and body composition of the basketball players from elite ranking of the competition Montenegro and Serbia as well as to make comparation between them. Forty-eight males were enrolled in the study, divided into two groups: twenty-four senior players from the First Basketball League of Montenegro and twenty-four senior players from the Serbian Superleague. Morphological characteristics were evaluated by a battery of four variables: body height, body weight, arm span and length of the leg. Body composition were evaluated by a battery of two variables: body mass index and fat percentage of body. The standard central and dispersive parameters of all variables were calculated. The significance of the differences between the Second League basketball players from Montenegro and Serbia was determined by a t-test for small independent samples. The results showed that a significant differences was no found for any variable among the group. Therefore, these findings may give coaches knowledge that Montenegrin players have a good morphological potential, in that segment are not lagging behind for the Serbian players, whose players make excellent results at international competitions.
\end{abstract}

Key words: Basketball, Morphological Characteristics, Montenegro, Serbia

\section{Uvod}

Košarka je danas jedan od najatraktivnijih sportova, zaokuplja pažnju mnogih diskursa i samim tim zahteva dublje rasvetljavanje kako sa teorijskog, tako i sa istraživačkog stanovišta (Vukašević, 2010). U početnoj fazi pojavljivanja košarka je bila namijenjena i dostupna širokom spektru zainteresovanih, što je brzo dovelo do nevjerovatne ekspanzije i popularnosti širom svijeta (Vukasevic, Spaic, \& Masanovic, 2018). Kroz svoju dugogodišnju istoriju doživjela je evoluciju od alternativne igre do visoko selektivne sportske grane u kojoj je uspjeh rezervisan isključivo za najtalentovanije i najsposobnije pojedince (Vukasevic, 2010). Karalejić i Jakovljević, (2001) u svojoj definiciji uspješnog košarkaša kao prvi i najvažniji element navode upravo antropometrijske karakteristike: longitudinalnu dimenzionalnost, tjelesna visina, sjedeća visina, raspon ruku, dužina ekstremiteta, stopala i šake. Zatim ističu transferzalnu dimenzionalnost, obime, masu tijela i potkožno masno tkivo. Pored ovih dimenzionalnosti, a u okviru antropometrijskih karakteristika, oni navode jos i kompoziciju tijela i somatotip igrača. Istraživanja mnogih autora potvrđuju ovu tvrdnju. Visina igračima omogućava da lakše dodju do lopte u odbrani i napadu, blokiraju protivnički napad i šut (Popovic, 2014). Tjelesna masa može uticati na brzinu, izdržljivost i snagu (Strel, 2006). Na kraju, dobro je poznato da masno tkivo može da kompromituje fizičke performance (Nikolaidis \& VassiliosKarydis, 2011), djelujući kao balast. Kod aktivnosti repetitivnog režima rada smanjuje performance a povećava potrošnju energije (Ramos-Campo et al., 2014).

Pripadnost sportiste jednoj sportskoj grani podrazumijeva njegov „biotip”, koji mu daje prednost da se bavi baš tim sportom u odnosu na druge (Masanovic, 2008). U svakom sportu i sportskoj disciplini postoje specifičnosti i različitosti u takmičarskoj

Correspondence:

Montenegro V.Vukasevic

Sport Basketball Club Vizura, Cara Dusana 105, 11080 Belgrade, Serbia

E-mail: velisavukasevic@yahoo.com 
strukturi, pa se nameće potreba za neprekidnim istraživanjem i potvrđivanjem u praksi upravo tih specifičnosti (Popovic, Smajic, Joksimovic, \& Masanovic, 2010; Vukotic, Corluka, Vasiljevic, \& Bubanja, 2018). Utvrđivanje biotipa, odnosno tjelesne kompozicije i konstitucije sportista, važan je faktor u procesu selekcije i izrade modela na osnovu kojeg se programira trenažni proces (Masanovic \& Vukasević, 2009; Popović, Mašanović, Molnar, \& Smajić, 2009; Gušić, Popovic, Molnar, Masanovic, \& Radakovic, 2017; Masanovic, Popovic, \& Bjelica, 2018; Vukotic, 2010; Vukotic, 2011; Vukotic, 2018). Bolje upoznavanje antropometrijskih karakteristika, tjelesne kompozicije i konstitucije sportista ima za cilj upravljanje ovim svojstvima, prilagođavanje sportskog treninga individualnim sposobnostima i mogućnost prognoziranja krajnjih dometa (Masanovic, 2009). Za sportski razvoj pojedinca, u svakoj sportskoj discipline, potreban je interdisciplinarni pristup, on će mu omogućiti da ispuni zadatke tokom procesa sportskog takmičenja ili sportskog treninga (Abernethy, 2005; Bjelica, Gardasevic, \& Vasiljevic, 2018; Bjelica, 2005, Bjelica, Popovic, \& Gardasevic, 2016a; Bjelica, Popovic, \& Gardasevic, 2016b; Bjelica, 2002; Bjelica, 2004; Bjelica, 2006a; Bjelica, 2006b; Bjelica \& Krivokapic, 2010; Bjelica \& Krivokapic, 2011; Bjelica \& Krivokapic, 2012; Gardasevic, Popovic, \& Bjelica, 2016; Masanovic, Vukotic, Bjelica, \& Popovic, 2018; Popovic, Bjelica, Vukotic, \& Masanovic, 2018; Sermaxhaj, Popović, Bjelica, Gardašević, \& Arifi, 2017; Vukasevic, Vukotic, \& Masanovic, 2018).

Savremena nauka ima za cilj da poboljša performance elitnih igrača i da omogući što precizniju identifikaciju talenata (Popovic et al., 2013). Ovaj process je veoma zahtjevan jer svaki sport iziskuje različitu tjelesnu građu koja sportisti omogućuje maksimalne performance za datu discipline (Popovic et al., 2014). Novija istraživanja antropometrijskih karakteristika idu i korak dalje, ukazujući na to da pripadnici istog sporta imaju specifična obilježja u odnosu na pozicije u timu na kojima igraju (Vasiljević, Bjelica, Popović, \& Gardašević, 2015), i zbog toga utvrđivanje antropometrijskih karakteristika predstavlja jednu od tri najčešće testiranie dimenzije sportista (Milanović, Jukić, Vuleta, Šimek, \& Šentija, 2005).

Morfološki statusi vrhunskih sportista su relativno homogeni, u zavisnosti od sporta, i mogu biti definisani kao modeli sportistskog postignuća (Mišigoj-Duraković, Matković, \& Medved, 1995). Svrha morfoloških dimenzija je da se poboljšaju mogućnosti u mnogim sportovima (Carter \& Heath, 1990).

Osnovni cilj ovog istraživanja je bio da se utvrdi postoje li razlike u nivou morfoloških karakteristika i tjelesne kompozicije između igrača Prve lige Crne Gore i igrača Superlige Srbije, takođe da se utvrdi da li igrači iz Crne Gore imaju dobar morfološki potencijal, odnosno zaostaju li za igračima iz Srbije koji postižu izuzetno dobre rezultate na navećim međunarodnim takmičenjima.

\section{Metode}

Uzorak ispitanika čini ukupno 48 košarkaša seniorskog uzrasta, podijeljen na dva subuzorka. Prvi subuzorak su činili 24 košarkaša koji nastupaju u Prvoj ligi Crne Gore, prosječne starosti $22.75 \pm 4.24$ godina, dok su drugi subuzorak činili 24 košarkaša koji nastupaju u Superligi Srbije, prosječne starosti $25.08 \pm 5.56$ godina.

Antropometrijsko istraživanje sprovedeno je uz poštovanje osnovnih pravila i principa vezanih za izbor mjernih instrumenata i tehnike mjerenja koji su standardizovani, prema upustvima Internacionalnog Biološkog Programa. Za potrebe ovog istraživanja izmjerene su četiri varijable morfoloških mjera: visina tijela (TV), težina tijela (TM), raspon ruku (RR), dužina noge (DN); i dvije varijable za procjenu tjelesnog sastava: procjenat masnog tkiva (PM) i indeks tjelesne mase (BMI). Za antropometrijsko merenje korišćeni su standardizovani merni instrumenti: antropometar po Martinu i vaga. Sve relevantne antropomotoričke dimenzije (osim morfološkog svojstva-raspona ruku koje je izmereno antropometrom u standardnim uslovima) su određene prema standardima internacionalnog biološkog programa. Za procjenu sastava tijela korišćena je tanita vaga, model BC-418MA. Princip rada ove vage je zasnovan na indirektnom mjerenju tjelesnog sastava, bezbjedan električni signal se šalje kroz tijelo preko elektroda smještenih u samostalnu jedinicu. Tanita vaga, zahvaljujući atletskom modu koje posjeduje, omogućava sportistima detaljno praćenje tjelesne težine, zdrastvenog stanja i kondicije, sa svim relevantnim parametrima.

Podaci dobijeni istraživanjem obrađeni su postupcima deskriptivne i komparativne statističke procedure. Za svaku varijablu su obrađeni centralni i disperzioni parametri kao i mjere asimetrije i spljoštenosti. Razlike u morfološkim dimenzijama i sastavu tijela košarkaša koji nastupaju u Prvoj ligi Crne Gore i Superligi Srbije utvrđene su primjenom diskriminativne parametrijske procedure, $\mathrm{t}$-testom za male nezavisne uzorke, sa statističkom značajnošću od $\mathrm{p}<0.05$.

\section{Rezultati}

U Tabelama 1 i 2 prikazani su osnovni deskriptivni statistički parametri antropometrijskih varijabli i tjelesnog sastava košarkaša elitnih rangova takmičenja dvije države, gdje su izračunate vrijednosti mjera centralne i disperzione tendencije i to: aritmetička sredina (Mean), standardna devijacija (Std. Dev.), varijansa (Variance), minimalne (Min) i maksimalne (Max) vrijednosti, koeficijenti zakrivljenosti (Skewness) i izduženosti (Kurtosis). Prvo su analizirani centralni i disperzioni parametri varijabli za procjenu morfoloških karakteristika i sastava tijela košarkaša koji nastupaju u Prvoj ligi Crne Gore (Tabela 1.).

Tabela 1. Centralni i disperzioni parametri varijabli za procjenu morfoloških dimenzija i tjelesnog sastava igrača Prve lige Crne Gore (N=24)

\begin{tabular}{llllllllll}
\hline & Min & Max & Mean & Std. D. & Variance & $\begin{array}{l}\text { Skewness } \\
\text { Stat. }\end{array}$ & \multicolumn{2}{l}{$\begin{array}{l}\text { Kurtosis } \\
\text { Stat. E. }\end{array}$} & \multicolumn{1}{l}{ Std. E. } \\
\hline TV $(\mathrm{cm})$ & 185.00 & 208.00 & 198.38 & 7.42 & 55.027 & -.425 & .472 & -1.153 & .918 \\
TM (kg) & 78.00 & 111.00 & 93.00 & 8.50 & 72.174 & .464 & .472 & -.126 & .918 \\
RR (cm) & 185.00 & 214.00 & 200.83 & 9.43 & 88.928 & -.282 & .472 & -1.559 & .918 \\
DN (cm) & 104.00 & 122.00 & 115.00 & 5.23 & 27.304 & -.680 & .472 & -.544 & .918 \\
BMI (kg/m $\left.{ }^{2}\right)$ & 21.00 & 26.00 & 23.67 & 1.50 & 2.232 & .117 & .472 & -1.186 & .918 \\
PM (\%) & 8.00 & 16.00 & 11.62 & 2.45 & 5.984 & -.009 & .472 & -1.038 & .918 \\
\hline
\end{tabular}


Na osnovu centralnih i disperzionih parametara, vrijednosti skjunisa i kurtozisa može se konstatovati da su sve varijable u granicama normalne raspodjele. Vidi se po vrijednosti skjunisa da dvije varijable: tjelesna masa i BMI imaju blagu asimetriju, ne i statistički značajnu u stranu slabijih rezultata jer imaju pozitivan predznak, dok ostale varijable imaju nega- tivan predznak što pokazuje da su rezultati desno od srednje vrijednosti tj među većim vrijednostima. Po vrijednosti kurtozisa se vidi da sve varijable pokazuju raspodjelu pljosnatiju od normalne, $\mathrm{tj}$ da ima više rezultata nagomilanih na repovima raspodjele.

Tabela 2. Centralni i disperzioni parametri varijabli zalkmmmmm procjenu morfoloških dimenzija i tjelesnog sastava igrača Superlige Srbije $(\mathrm{N}=24)$

\begin{tabular}{|c|c|c|c|c|c|c|c|c|c|}
\hline & \multirow[t]{2}{*}{ Min } & \multirow[t]{2}{*}{ Max } & \multirow[t]{2}{*}{ Mean } & \multirow[t]{2}{*}{ Std. D. } & \multirow[t]{2}{*}{ Variance } & \multicolumn{2}{|c|}{ Skewness } & \multicolumn{2}{|c|}{ Kurtosis } \\
\hline & & & & & & Stat. & Std. E. & Stat. & Std. E. \\
\hline $\mathrm{TV}(\mathrm{cm})$ & 183.00 & 215.00 & 200.25 & 7.92 & 62.717 & -.054 & .472 & -.224 & .918 \\
\hline TM (kg) & 80.00 & 116.00 & 96.63 & 9.84 & 96.853 & .503 & .472 & -.620 & .918 \\
\hline $\mathrm{RR}(\mathrm{cm})$ & 184.00 & 226.00 & 204.08 & 10.55 & 111.297 & .251 & .472 & -.498 & .918 \\
\hline $\mathrm{DN}(\mathrm{cm})$ & 108.00 & 129.00 & 117.88 & 4.89 & 23.94 & .027 & .472 & .357 & .918 \\
\hline $\mathrm{BMI}\left(\mathrm{kg} / \mathrm{m}^{2}\right)$ & 18.82 & 26.78 & 24.07 & 1.62 & 2.634 & -1.164 & .472 & 3.908 & .918 \\
\hline PM (\%) & 8.00 & 16.10 & 10.67 & 2.14 & 4.567 & .896 & .472 & .354 & .918 \\
\hline
\end{tabular}

$\mathrm{Na}$ osnovu centralnih i disperzionih parametara, vrijednosti skjunisa i kurtozisa košarkaša koji nastupaju u Superligi Srbije, može se konstatovati da su sve varijable u granicama normalne raspodjele i da su vrijednosti približno slične košarkašima predhodno analizirane grupe. Vidi se po vrijednosti skjunisa da četiri varijable: tjelesna masa, raspon ruku, dužina noge i procjenat masti imaju blagu asimetriju, ne i statistički značajnu u stranu slabijih rezultata jer imaju pozitivan predznak, dok ostale varijable imaju negativan predznak što pokazuje da su rezultati desno od srednje vrijednosti tj me- đu većim vrijednostima. Negativne vrijednosti kurtozisa kod varijabli tjelesne visine, tjelesne mase i raspona ruku pokazuju da je raspodjela pljosnatija od normale, što govori da ima više rezultata nagomilanih na repovima, dok pozitivne vrijednosti dužine noge, BMI i procenta masti pokazuju da je raspodjela šiljatija od normale što govori da je veliki broj rezultata za ove varijable raspoređeno oko aritmetičke sredine. Da bi se moglo utvrditi da li ima statistički značajne razlike u analiziranim varijablama kod košarkaša elitnih rangova takmičenja ove dvije zemlje, primjenjena je statistička procedura t-test (Tabela 3 ).

Tabela 3. Vrijednosti t-testa izmedju aritmetičkih sredina varijabli za procjenu morfoloških dimenzija i tjelesnog sastava igrača Prve lige Crne Gore ( $\mathrm{N}=24)$ i Superlige Srbije ( $\mathrm{N}=24)$

\begin{tabular}{|c|c|c|c|c|c|c|c|}
\hline Varijable & Lige & Mean & Std. D. & Std. E. M. & t-test & Sig. & $\begin{array}{c}\text { Mean } \\
\text { Difference }\end{array}$ \\
\hline \multirow[b]{2}{*}{$\mathrm{TV}(\mathrm{cm})$} & Crna Gora & 198.38 & 7.418 & 1.514 & \multirow[b]{2}{*}{-.847} & \multirow[b]{2}{*}{.402} & \multirow[b]{2}{*}{-1.875} \\
\hline & Srbija & 200.25 & 7.919 & 1.617 & & & \\
\hline \multirow{2}{*}{ TM (kg) } & Crna Gora & 93.00 & 8.496 & 1.734 & \multirow{2}{*}{-1.366} & \multirow{2}{*}{.179} & \multirow{2}{*}{-3.625} \\
\hline & Srbija & 96.63 & 9.841 & 2.009 & & & \\
\hline \multirow{2}{*}{$\mathrm{RR}(\mathrm{cm})$} & Crna Gora & 200.83 & 9.430 & 1.925 & \multirow{2}{*}{-1.125} & \multirow{2}{*}{.266} & \multirow{2}{*}{-3.250} \\
\hline & Srbija & 204.08 & 10.55 & 2.153 & & & \\
\hline \multirow{2}{*}{$\mathrm{DN}(\mathrm{cm})$} & Crna Gora & 115.00 & 5.225 & 1.067 & \multirow{2}{*}{-1.968} & \multirow{2}{*}{.055} & \multirow{2}{*}{-2.875} \\
\hline & Srbija & 117.88 & 4.893 & .999 & & & \\
\hline \multirow{2}{*}{$\mathrm{BMI}\left(\mathrm{kg} / \mathrm{m}^{2}\right)$} & Crna Gora & 23.67 & 1.494 & .305 & \multirow{2}{*}{-.742} & \multirow{2}{*}{.462} & \multirow{2}{*}{-.333} \\
\hline & Srbija & 24.00 & 1.615 & .333 & & & \\
\hline \multirow{2}{*}{ PM (\%) } & Crna Gora & 11.73 & 2.372 & .484 & \multirow{2}{*}{.1 .63} & \multirow{2}{*}{.110} & \multirow{2}{*}{1.062} \\
\hline & Srbija & 10.67 & 2.137 & .436 & & & \\
\hline
\end{tabular}

Na osnovu dobijenih vrijednosti rezultata t-testa, može se primijetiti da ne postoje statistički značajne razlike na nivou značajnosti $\mathrm{p}<0.05$. što pokazuje dobru slektiranost igrača Prve lige Crne Gore u odnosu na igrače Superlige Srbije. Može se konstatovati da komparativna analiza morfoloških karakteristika i tjelesne kompozicije ne pokazuje statistički značajnu razliku u između igrača koji se takmiče u elitnom rangu takmičenja ove dvije zemlje.

\section{Diskusija}

Predhodna istraživanja govore da su košarkaši značajno viši od prosjeka opšte populacije. Razlog tome pripisuje se uslovima igre i potrebi da se lopta veliki dio vremena nalazi iznad glave (Guarav, 2010). Takođe, kao razlog se navodi i visi- na na kojoj se nalazi odbruč i konstantna potreba da se nadvisi protivnik. Prednost visokih igrača je mogućnost da šutiraju sa kraće distance, da imaju viši dohvat u skoku za loptom a takođe i u bloku. Potvrda ovome je prosječna visina profesionalnih košarkaša Slovenije koji su pobijedili na posljednjem evropskom prvenstvu. Njihova prosječna visina bila je $199.5 \mathrm{~cm}$, dok je prosječna visina drugoplasirane i trećeplasirane ekipe prelazila dva metra.

Osnovni cilj ovog istraživanja je bio da se utvrdi postoje li razlike u morfološkim karakteristika i sastavu tijela između igrača koji nastupaju u elitnom takmicarskom rangu Crne Gore i Srbije. Takođe da se utvrdi imaju li igrači iz Crne Gore dobar morfološki potencijal, odnosno zaostaju li morfološkim karakteristikama za igračima iz Srbije koji postižu značajnije 
rezultate na navećim međunarodnim takmičenjim. Uzorak od ukupno 48 ispitanika je podijeljen na dva subuzorka. Prvi subuzorak ispitanika su činila 24 igrača iz Crne Gore prosječne starosti $22.75 \pm 4.24$ godine, dok su drugi subuzorak činila 24 igrača iz Srbije prosječne $25.08 \pm 5.56$ godina. Rezultati su dobijeni praćenjem pet varijabli u prostoru morfoloških dimenzija i tjelesnog sastava. Uvidom u dobijene parametre se može zaključiti da se radi o profesionalnim sportistima. Vidi se da su igrači obije lige približnih srednjih vrijednosti analiziranih varijabli, što ne čudi jer se radi o igračima najkvalitetnijih timova pomenutog ranga takmičenja u Crnoj Gori i Srbiji gdje je velika koncetracija kvalitetnih igrača. Takođe prosječna tjelesna visina igrača obije lige značajno je viša od prosjeka opšte populacije izmjerenog na teritoriji Crne Gore i Srbije (Popović, Bjelica, Molnar, Jakšić, \& Akpinar, 2013; Popovic, 2017). Zaključujemo da je selekcija igrača dobro obavljena, što takodje nije iznenadjenje s obzirom da je karakteristika ovog regiona, da $28 \%$ ispitanika opšte populacije dostiže visinu od $190 \mathrm{~cm}$ ili više (Bjelica, Popović, Kezunović, Petković, Jurak, \& Grasgruber, 2012; Popović, Bjelica, Tanase, i Milašinović, 2015; Popović, Bjelica, Georgijev, Krivokapić, \& Milašinović, 2017; Popovic, 2016; Popovic, 2017; Arifi, Gardasevic, \& Masanovic, 2018; Gardasevic, Masanovic, \& Arifi, 2018). Vrijednosti dobijene t-testom, pokazuju nam da statistički značajne razlike između subuzoraka ni kod jednog od izmjerenih parametara ne postoje. To nas navodi da zaključimo kako crnogorski igrači posjeduju dobar morfološki potencijal, i ne zaostaju morfološkim karakteristikama za igračim Srbije koji postižu značajne rezultate na najvećim međunarodnim takmičenjima. $\mathrm{Na}$ osnovu toga možemo zaključiti da razloge zbog čega su rezultati selekcija i timova Crne Gore nešto slabiji u odnosu na rezultate selekcija i timova iz Srbije treba tražiti kod nekih drugih parametara od kojih takođe zavisi postizanje uspjeha.

Rezultati koji su dobijeni ovim istraživanjem mogu poslužiti kao modelni parametri u procjenjivanim varijablama za sve ostale igrače istog ranga takmičenja u Crnoj Gori i Srbiji, jer su analizirani igrači članovi najkvalitetnijih timova. Treba napomenuti da igrači koje žele uspješno nastupati u ligama gdje se igra najkvalitetnija košarka, moraju imati karakteristike utvrđene standardima za taj sport, a to se prije svega ogleda u morfološkim dimenzijama i tjelesnom sastavu.

\section{Acknowledgements}

There are no acknowledgements.

\section{Conflict of Interest}

The authors declare that there are no conflicts of interest.

Received: 1 July 2018 | Accepted: 29 July 2018 | Published: 29 October 2018

\section{References}

Abernethy, B. (2005). The biophysical foundations of human movement. Champaign, IL: Human Kinetics.

Arifi, F., Gardasevic, J., \& Masanovic, B. (2018). Relationship between foot length measurements and body height: A prospective regional study among adolescents in central region of Kosovo. Sport Mont, 16(3), 7579. doi: $10.26773 / \mathrm{smj} .181013$

Bjelica, D. (2002). Opšti pojmovi sportskog treninga: (skraćena verzija). Podgorica: Crnogorska sportska akademija.

Bjelica, D. (2004). Uticaj sportskog treninga na antropomotoričke sposobnosti: (fudbalskih kadeta Crne Gore). Podgorica: Crnogorska sportska akademija.

Bjelica, D. (2005). Sistematizacija sportskih disciplina $i$ sportski trening. Podgorica: Crnogorska sportska akademija.

Bjelica, D. (2006a). Sportski trening. Podgorica: Crnogorska sportska akademija.
Bjelica, D. (2006b). Teorijske osnove tjelesnog i zdrastvenog obrazovanja. Podgorica: Crnogorska sportska akademija.

Bjelica, D., Gardasevic, J., \& Vasiljevic, I. (2018). Differences in the morphological characteristics and body composition of football players FC Sutjeska and FC Mladost in Montenegro. Journal of Anthropology of Sport and Physical Education, 2(2), 31-5. doi: 10.26773/jaspe.180406

Bjelica, D., i Krivokapić D. (2012). Uticaj fizičkog vježbanja na psihomotorne funkcije starijih osoba. Zbornik radova Druge međunarodne konferencije Sportske nauke izdravlje, Banja Luka: Panaevropski univerzitet APEIRON, 191-6.

Bjelica, D., i Krivokapić, D. (2010). Teorijske osnove fizičke kulture. Nikšić: Fakultet za sport i fizičko vaspitanje Univerziteta Crne Gore.

Bjelica, D., i Krivokapić, D. (2011). Teorija igre. Nikšić: Fakultet za sport i fizičko vaspitanje Univerziteta Crne Gore.

Bjelica, D., Popović, S., i Gardašević, J. (2016a). Modeli fizičke pripreme vrhunskih sportaša i doziranje opterećenja. Zbornik radova 14. godišnje međunarodne konferencije "Kondicijska priprema sportaša" (185-189), Zagreb: Udruga kondicijskih trenera Hrvatske.

Bjelica, D., Popović, S., i Gardašević, J. (2016b). Opći principi planiranja i programiranja fizičkih priprema sportaša. Zbornik radova 14. godišnje međunarodne konferencije "Kondicijska priprema sportaša" (190-192) Zagreb: Udruga kondicijskih trenera Hrvatske.

Bjelica, D., Popović, S., Kezunović, M., Petković, J., Jurak, G., \& Grasgruber, P. (2012). Body Height and Its Estimation Utilizing Arm Span Measurements in Montenegrin Adults. Anthropological Notebooks, $18(2), 69-83$.

Carter, J.E.L., \& Heath, B.H. (1990). Somatotyping-Development and application. Cambridge, United Kingdom: Cambridge University Press.

Gardasevic, J., Masanovic, B., \& Arifi, F. (2018). Relationship between tibia length measurements and standing height: A prospective regional study among adolescents in southern region of Kosovo. Sport Mont, 16(3), 51-55. doi: 10.26773/smj.181009

Gardašević, J., Popović, S., \& Bjelica, D. (2016). After preparation period ball shooting accuracy at players U15. In Abstract Book of the 8th Conference for Youth Sport (88), Ljubljana: University of Ljubljana, Faculty of Sport.

Gaurav, V., Singh, M., \& Singh, S. (2010). Anthropometric characteristics, somatotyping and body composition of volleyball and basketball players. Journal of Physical Education and Sports Management 1(3), 28-32.

Gusic, M., Popovic, S., Molnar, S., Masanovic, B., \& Radakovic, M. (2017). SportSpecific Morphology Profile: Differences in Anthropometric Characteristics among Elite Soccer and Handball Players. Sport Mont, 15(1),3-6.

Karalejic, M. \& Jakovljevic, S. (2008). Teorija i metodika košarke. Beograd: Fakultet sporta i fizièkog vaspitanja.

Masanovic, B. (2008). Determination of body composition of athletes. Unpublished Master Thesis. Novi Sad: Faculty of Sport and Physical Education.

Masanovic, B. (2009). Differences of anthropometrical status on top level handball players and non sportsmen. Sport Mont, 6(18-19-20), 569-75.

Masanovic, B., \& Vukasevic, V. (2009). Differences of anthropometrical status on basketball and handball players in junior stature. Sport Mont, 6(1819-20), 576-82.

Masanovic, B., Popovic, S., \& Bjelica, D. (2018). Comparative Study of Anthropometric Measurement and Body Composition Between Junior Soccer and Volleyball Players From National League. In Book of Abstracts 15th International Scientific Conference on Transformation Process in Sport "Sport Performance" (58), Podgorica: Montenegrin Sports Academy.

Masanovic, B., Vukotic, M., Bjelica, D., \& Popovic, S. (2018). Describing Physical Activity Profile of Older Montenegrin Males Using the International Physical Activity Questionnaire (IPAQ). In Book of Abstracts 15th International Scientific Conference on Transformation Process in Sport "Sport Performance" (61), Podgorica: Montenegrin Sports Academy.

Milanović, D., Jukić, I., Vuleta, D., Šimek, S. \& Šentija D. (2005). Measurement and evaluation of fitness characteristics of Croatian handball players. Zbornik radova Sports Kinetics' 2005 „Scientific Fundaments of Human and Sport Practice", (444-8).

Mišigoj-Duraković, M., Matković, B., \& Medved, R. (1995). Morfološka antropometrija $u$ športu. Morphological anthropometry in sports. Zagreb, Croatia: Fakultet za fizičku kulturu.

Nikolaidis, P.T., \& Vassilios-Karydis, N. (2011). Physique and body composition in soccer players across adolescence. Asian J Sports Med, 2(2), 75-82.

Popovic, S. (2016). Body Height and its Estimation Utilizing Arm Span Measurements in Montenegrin Adults: National Survey. In Book of Summaries of 11th FIEP European Congress "Anthropological Aspects of Sport, Physical Education and Recreation" (5-6), Banjaluka: University of Banjaluka, Faculty of Physical Education and Sport.

Popovic, S. (2017). Local Geographical Differences in Adult Body Height in Montenegro. Montenegrin Journal of Sports Science and Medicine, 6(1), 81-7. 
Popovic, S. (2017). Local Geographical Differences in Adult Body Height in Montenegro. Monten. J Sports Sci Med, 6(1), 81-7.

Popovic, S., Akpinar, S., Jaksic, D., Matic, R., \& Bjelica, D. (2013). Comparative Study of Anthropometric Measurement and Body Composition between Elite Soccer and Basketball Players. International Journal of Morphology, 31(2), 461-7.

Popović, S., Bjelica, D., Georijev, G., Krivokapić, D. \& Milašinović, R. (2017). Body height and its estimation utilizing arm span Measurements in Macedonian. The anthropologis, 24(3), 737-45.

Popović, S., Bjelica, D., Molnar, S. Jakšić, D, \& Akpinar, S. (2013). Body height and its estimation utilizing arm span Measurements in serbian adults. Int. J. Morphol., 31(1), 271-9.

Popović, S., Bjelica, D., Tanase, G., \& Milašinović, R. (2015). Body Height and Arm Span in Bosnian and Herzegovinian Adults, Monten. J. Sports Sci. Med. 4(1), 29-36.

Popovic, S., Bjelica, D., Vukotic, M., \& Masanovic, B. (2018). Describing Physical Activity Profile of Older Montenegrin Females Using the International Physical Activity Questionnaire (IPAQ). In Book of Abstracts 15th International Scientific Conference on Transformation Process in Sport "Sport Performance" (60-61), Podgorica: Montenegrin Sports Academy.

Popović, S., Mašanović, B., Molnar, S., \& Smajić, M. (2009). Determining Body Composition of Top Level Athletes. Teme, 33(4), 1534-49.

Popovic, S., Smajic, M., Joksimovic, A., \& Masanovic, B. (2010). The differences in body composition between football players of different rank competitions. Sport Mont, 8(23-24), 362-7.

Popovic. S., Bjelica, D., Jaksic, D., \& Hadzic, R. (2014). Comparative Study of Anthropometric Measurement and Body Composition between Elite Soccer and Volleyball Players. International Journal of Morphology, 32(1), 267-74

Ramos-Campo, D.J., Martinez-Sanchez, F., Esteban-Garcia, P., Rubio-Arias, J.A., Bores, C.A., Clemente-Suarez, V.J., \& Jimenez-Diaz, J.F. (2014). Body Composition Features in Different Playing Position of Professional Team Indoor Players: Basketball, Handball and Futsal. Int. J. Morphol., 32(4), 1316-24.

Sermaxhaj, S., Popović, S., Bjelica, D., Gardašević, J., \& Arifi, F. (2017). Effect of recuperation with static stretching in isokinetic force of young foot- ball players. Journal of Physical Education and Sport, 17(3), 1948-53. doi: 10.7752/jpes.2017.03191

Strel, J. (2006). Correlation of physical characteristics and general endurance: A comparison of 7- to 19-year-old pupils between 1983, 1993 and 2003. Anthropological Notebooks 12(2), 113-28.

Vasiljević, I., Bjelica, D., Popović, S., \& Gardašević, J. (2015). Analysis of nutrition of preschool-age and younger school-age boys and girls. Journal of Physical Education and Sport, 15(3), 426 - 8.

Vukasevic, V. (2010). Uporedna analiza morfoloških i motoričkih dimenzija košarkaša prvog $i$ drugog ranga takmičenja srbije $i$ crne gore. Neobjavljena magistarska teza. Beograd: "Alfa" BK Univerzitet, Fakultet za menadžment u sportu.

Vukasevic, V., Spaic, S., \& Masanovic, B. (2018). Comparative study of anthropometric measurement and body composition between the basketball player first and second league in Montenegro. Journal of Anthropology of Sport and Physical Education, 2(3), 61-65. doi: 10.26773/jaspe.180711

Vukasevic, V., Vukotic, M., \& Masanovic, B. (2018). Comparative study of morphological characteristics and body composition between basketball players from second leagues in Montenegro and Serbia. Journal of Anthropology of Sport and Physical Education, 2(3), 21-25. doi: 10.26773/ jaspe. 180704

Vukotić, M. (2010). Nivo morfoloških karakteristika, motoričkih i funkcionalnih sposobnosti sportista različitog sportskog usmjerenja. Neobjavljena magistarska teza. Nikšić: Fakultet za sport i fizičko vaspitanje.

Vukotić, M. (2011). Differences of anthropometric characteristic and motor abilities of different sport orientation. Sport Mont, 9(28-29-30), 112-8.

Vukotic, M. (2018). Comparative analysis of antropmtric indicators of sportisis of different soprts guidance. In Book of Abstracts 15th International Scientific Conference on Transformation Process in Sport "Sport Performance" (75-76), Podgorica: Montenegrin Sports Academy.

Vukotić, M., Čorluka, M., Vasiljević, I., \& Bubanja, M. (2018). Differences in the Morphological Characteristics and Body Composition of Handball Players WHC Levalea in Montenegro and WHC Grude in Bosnia and Herzegovina. J. Anthr. Sport Phys. Educ. 2(2018)2,49-53. DOI: 10.26773/ jaspe.180409 